\title{
Unusual Laboratory Results Suggest Late Development of Zika Virus-Specific Neutralizing Antibodies
}

\author{
Benjamin D. Hornstein ${ }^{\text {a, d }}$, Rebecca J. Rubinstein ${ }^{\text {a }}$ Patricia Peña ${ }^{a}$, Leann Liu ${ }^{a}$, \\ Brian C. Reed ${ }^{b}$, Dana Beckham ${ }^{\mathrm{a}}$, Les Becker ${ }^{\mathrm{a}}$, Umair A. Shah ${ }^{\mathrm{c}}$
}

\begin{abstract}
Zika virus is an emerging infectious disease that is not yet fully understood. Laboratory testing guidelines were established based on research on related flaviviruses, such as dengue. However, recent evidence has suggested differences in immunological response to infections between dengue and Zika virus. Interim US Centers for Disease Control and Prevention (CDC) guidance in interpretation of Zika laboratory test results cannot cover every possible scenario. Here, we present a case of an asymptomatic patient with conflicting laboratory results from a specimen drawn 8 days after moving to the USA from an area of Zika risk. The patient was found to be both positive and negative for Zika virus RNA by different laboratories, positive for Zika-specific IgM antibodies and negative for Zika-specific and dengue-specific neutralizing antibodies. Because this specimen was drawn shortly after a potential exposure, we hypothesized that the patient had been infected, but had yet to develop neutralizing antibodies against Zika. After drawing a new specimen approximately 9 weeks after the original, the patient was found to have neutralizing antibodies, suggesting that she had been recently infected with Zika virus. This case illustrates that patients with unusual laboratory results should be considered in the context of their potential risk factors and the nuances of interpreting laboratory testing.
\end{abstract}

Keywords: Zika virus; Laboratory testing; Pregnancy

\section{Introduction}

Prior to the 2007 outbreak on Yap Island [1], Zika virus was of little public health interest. After Zika virus infection was linked to birth defects in 2015 [2], concern over this mosquitoborne illness grew. Little was known about this virus at the

Manuscript submitted April 16, 2018, accepted May 3, 2018

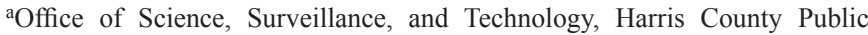
Health, Houston, TX, USA

${ }^{b}$ Disease Control \& Clinical Prevention, Harris County Public Health, Houston, TX, USA

cHarris County Public Health, Houston, TX, USA

${ }^{\mathrm{d}}$ Corresponding Author: Benjamin D. Hornstein, 2223 W Loop South, Houston, TX 77027, USA. Email: Benjamin.Hornstein@phs.hctx.net

doi: https://doi.org/10.14740/jmc3029w time, and researchers, physicians and public health officials are still trying to learn about the natural disease course of Zika virus infection. The US Centers for Disease Control and Prevention (CDC) have issued guidelines for whom to test for Zika virus [3], treatment and care for pregnant women with potential exposure [4], treatment and care of infants of women with potential Zika exposure during pregnancy [5], protection from sexual transmission of Zika [6] and how to interpret Zika laboratory test results [7]. These guidelines have been updated several times since the first case of Zika virus disease in the USA to reflect additional knowledge about Zika learned from research and observations [8]. Here, we present a case that may be useful for understanding laboratory results in the context of future potential Zika virus cases.

The latest Zika testing guidelines from $\mathrm{CDC}$, issued in July 2017, do not recommend routine testing of asymptomatic pregnant women with possible Zika virus exposure, but instead recommend a "shared decision model" where the patient and provider jointly weigh the risks and benefits of Zika virus testing [8]. This model also allows for additional recommendations from state or local health departments based on local and regional Zika risks. The Texas Department of State Health Services recommends testing all pregnant women with recent travel to an area of Zika risk, based on their testing guidelines published in August 2017 [9]. Testing is recommended within 12 weeks of exposure, and patients should be tested both by Zika virus-specific nucleic acid test (NAT) and by enzymelinked immunosorbent assay (ELISA) to detect immunoglobulin $\mathrm{M}(\operatorname{IgM})$ antibodies that bind Zika virus [8]. A positive Zika NAT is sufficient to confirm Zika virus infection, but any non-negative ELISA result must be sent to a CDC-approved laboratory for confirmatory plaque-reduction neutralization testing (PRNT) to distinguish between Zika-specific antibodies, dengue-specific antibodies and false positive results [7].

For dengue virus, which is closely related to Zika virus, IgM antibodies are typically detectable 3 - 6 days after symptom onset [10]. The length of time that Zika virus or Zika virus-specific antibodies are detectable is highly variable [11], and little is known about the timing of IgM and neutralizing antibody production in asymptomatic Zika virus infection.

\section{Case Report}

Patient A is a pregnant minor female who moved from Mexico 
Table 1. List of Zika Laboratory Tests Performed on Patient A and Their Results. The First Specimen Was Drawn 8 days After Arrival From an Area of Zika Risk, and the Second Specimen Was Drawn 74 Days After Arrival in the USA

\begin{tabular}{llll} 
Specimen & Laboratory & Test performed & Result \\
\hline First specimen & A & Zika NAT & Negative \\
First specimen & A & Zika IgM & Presumptive positive \\
First specimen & B & Zika NAT & Positive \\
First specimen & B & Zika IgM & Presumptive positive \\
First specimen & C & Zika PRNT & $<1: 10$ (negative) \\
First specimen & C & Dengue PRNT & $<1: 10$ (negative) \\
Second specimen & A & Zika NAT & Negative \\
Second specimen & A & Zika IgM & Presumptive positive \\
Second specimen & B & Zika NAT & Negative \\
Second specimen & B & Zika IgM & Presumptive positive \\
Second specimen & C & Zika PRNT & $\geq 1: 20$ (positive) \\
Second specimen & C & Dengue PRNT & $<1: 10$ (negative) \\
\hline
\end{tabular}

Laboratories A, B, and C all refer to Public Health laboratories. NAT: nucleic acid testing referring to reverse transcriptase polymerase chain reaction (RT-PCR); IgM: immunoglobulin M referring to enzyme-linked immunosorbent assay (ELISA) testing the presence of IgM antibodies; PRNT: plaque reduction neutralization test.

to Texas in 2017 during her second trimester. The patient went to an Emergency Department 8 days after her arrival in Texas with headache, fever and a lack of fetal movement, at which point, a specimen was drawn for Zika virus testing in light of her recent residence in Mexico. The specimen was sent to the Laboratory A public health laboratory for Zika NAT and Zika ELISA testing, where the NAT came back negative and the ELISA came back presumptive positive. The specimen was forwarded to the Laboratory B public health laboratory for retesting before it was sent to the Laboratory $\mathrm{C}$, which has been approved by CDC to conduct PRNT. The Laboratory B results were positive for Zika virus by NAT and presumptive positive by ELISA. Despite the discordant NAT results, the positive IgM ELISA from both laboratories suggested that this was a positive case of Zika virus infection. The Laboratory C PRNT results later came back negative for both dengue and Zika neutralizing antibodies. Upon later retesting by NAT, Laboratory A yielded a negative result again from the same specimen.

These results led the HCPH Epidemiology program to postulate several hypotheses. The first hypothesis is that the patient did not actually have Zika virus infection, but yielded a false-positive NAT and two false positive ELISA results. The second hypothesis is that the patient did have a Zika virus infection, but yielded a false negative NAT and false negative PRNT. The final hypothesis is that the patient had Zika virus infection, had developed Zika-specific IgM antibodies at the time of testing, but had not yet developed neutralizing antibodies. This also implies that the initial NAT was a false negative.

To distinguish between these hypotheses, $\mathrm{HCPH}$ worked with the patient and her provider to repeat the Zika testing, nearly 10 weeks after her initial testing. This time, both laboratory A and B found a negative Zika NAT result and a presump- tive positive IgM result. Laboratory C conducted PRNT, which came back positive for Zika neutralizing antibodies and negative for dengue neutralizing antibodies. A summary of all the results is given in Table 1. These additional results suggested that the patient did, in fact, have Zika virus infection, but did not yet have neutralizing antibodies when the first blood specimen was drawn.

\section{Discussion}

This is the first reported case of a patient with detectable Zika virus-specific IgM antibodies, but without Zika virus-specific neutralizing antibodies, after a true infection. Typically, a presumptive positive Zika ELISA result followed by negative PRNTs would indicate that the original ELISA was a false positive. However, as this case illustrates, if the potential infection was recent enough, the ELISA could be a true positive, but too soon for neutralizing antibodies. In this case, one of the two NATs performed came back positive, indicating that the patient was still viremic at the time of the first blood draw. Logically, if a patient is infected with Zika virus, at any given time, either the patient will still be viremic, or they will have developed neutralizing antibodies to eliminate the virus. This case, therefore, illustrates the importance of performing both NAT and ELISA tests concurrently, as the current CDC guidelines recommend. It also illustrates that cases where the ELISA appears to have been a false positive be evaluated critically in case the specimen was drawn less than 2 weeks after the potential exposure. The lesson for providers and public health practitioners is to carefully consider, for each patient with unusual laboratory results, the specific timing of exposure and testing, and to understand the nuances of laboratory testing. This is especially true for emerging infectious diseas- 
es such as Zika.

\section{Acknowledgments}

We would like to acknowledge Juana "Janie" Saucedo from the Zika Local Health Department Initiative by the CDC; the staff of the Office of Public Health Preparedness and Response at Harris County Public Health; the staff of the Division of Disease Control and Clinical Prevention at Harris County Public Health; Kelly Broussard and Nicole Evert from Texas Department of State Health Services Zoonosis Control Branch; all the laboratory staff from City of Houston LRN and Texas Department of State Health Services LRN; Blanca Alaniz and Dr Violeta Chávez from Harris Health System; and all of our internal partners at $\mathrm{HCPH}$ who contributed to this case report. Authors $\mathrm{BH}$ and RR are funded by grants NU90TP921869-01-02 and U50CK000378 from the CDC awarded to Texas Department of State Health Services.

\section{Conflict of Interest}

The authors declare no conflict of interest.

\section{Grant Support}

Authors BH and RR are funded by grants NU90TP921869-01-02 and U50CK000378 from the CDC awarded to Texas Department of State Health Services.

\section{References}

1. Zika Virus Outbreak on Yap Island, Federated States of Micronesia | NEJM [Internet]. [cited 2018 Jan 29]. Available from: http:/www.nejm.org/doi/10.1056/NEJMoa0805715.

2. Rasmussen SA, Jamieson DJ, Honein MA, Petersen LR. Zika virus and birth defects - reviewing the evidence for causality. N Engl J Med. 2016;374(20):1981-1987.

3. HAN Archive - 00385|Health Alert Network (HAN) [Internet]. [cited 2018 Jan 19]. Available from: https://emergency.cdc.gov/han/han00385.asp.

4. Petersen EE, Staples JE, Meaney-Delman D, Fischer M, Ellington SR, Callaghan WM, Jamieson DJ. Interim guidelines for pregnant women during a zika virus outbreak - United States, 2016. MMWR Morb Mortal Wkly Rep. 2016;65(2):30-33.

5. Fleming-Dutra KE, Nelson JM, Fischer M, Staples JE, Karwowski MP, Mead P, Villanueva J, et al. Update: interim guidelines for health care providers caring for infants and children with possible zika virus infection - United States, February 2016. MMWR Morb Mortal Wkly Rep. 2016;65(7):182-187.

6. Brooks JT, Friedman A, Kachur RE, LaFlam M, Peters PJ, Jamieson DJ. Update: interim guidance for prevention of sexual transmission of zika virus - United States, July 2016. MMWR Morb Mortal Wkly Rep. 2016;65(29):745747.

7. Rabe IB, Staples JE, Villanueva J, Hummel KB, Johnson JA, Rose L, Mts, et al. Interim guidance for interpretation of zika virus antibody test results. MMWR Morb Mortal Wkly Rep. 2016;65(21):543-546.

8. Oduyebo T, Polen KD, Walke HT, Reagan-Steiner S, Lathrop E, Rabe IB, Kuhnert-Tallman WL, et al. Update: interim guidance for health care providers caring for pregnant women with possible zika virus exposure - United States (Including U.S. Territories), July 2017. MMWR Morb Mortal Wkly Rep. 2017;66(29):781-793.

9. Zika Health Alert - 08/24/17 [Internet]. [cited 2018 Jan 8]. Available from: http://www.dshs.texas.gov/news/releases/2017/HealthAlert-08242017.aspx.

10. Muller DA, Depelsenaire AC, Young PR. Clinical and laboratory diagnosis of dengue virus infection. J Infect Dis. 2017;215(suppl_2):S89-S95.

11. Barzon L, Percivalle E, Pacenti M, Rovida F, Zavattoni M, Del Bravo P, Cattelan AM, et al. Virus and antibody dynamics in travelers with acute zika virus infection. Clin Infect Dis. 2018;66(8):1173-1180. 